\title{
The timing is right to end snakebite deaths in South Asia
}

\section{Regional collaboration is crucial to end preventable deaths and disability from snakebites in South Asia, say Ravikar Ralph and colleagues}

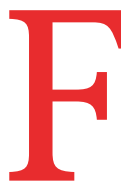

ive million snakebites occur globally each year, causing between 81000 and 138000 deaths and nearly 400000 amputations and other permanent disabilities. ${ }^{1}$ South Asia has the highest incidence of venomous snakebites in the world. ${ }^{2}$ Within the region, Bangladesh, India, Nepal, Pakistan, and Sri Lanka together constitute nearly $70 \%$ of global snakebite mortality. ${ }^{3}$

The World Health Organization recognised snakebite as a neglected tropical disease in 2017, giving it high priority for large scale action and research. ${ }^{4}$ A resolution passed in the World Health Assembly in May 2018 urged member states to step up efforts to tackle snakebite. ${ }^{56}$ It is important that regional mitigation efforts in South Asia reflect these objectives. In this paper, we explore the determinants of poor clinical outcomes with snakebite in South Asia and propose priority actions for governments to achieve the vision of zero deaths from snakebite.

\section{Disease burden}

The region is a biodiversity hotspot for venomous snake species. The sociodemographic and occupational profile of the population contributes to increased risk of snake-human encounters. Snakebites are largely an agrarian occupational hazard in South Asia. Box 1 describes the medically important snake spe-

\section{KEY MESSAGES}

- South Asia has the highest burden of snakebite envenoming in the world and contributes to $70 \%$ of global snakebite mortality

- Inadequate first aid, delayed treatment access, and suboptimal treatment contribute to poor outcomes

- The global focus on snakebite as a neglected tropical disease provides an opportune time for South Asian countries to strengthen regional cooperation and investment in research on epidemiology, treatment, and prevention cies in South Asia and demographic profile of groups commonly affected.

Lack of systematic preventive measures at community and national levels contributes to the high incidence of snakebite. Figure 1 shows snakebite incidence and associated mortality in South Asian countries. These estimates are drawn from extrapolations of hospital records and community surveys, and likely underestimate the problem. ${ }^{78}$ Long term complications occur in around $15 \%$ of survivors and include musculoskeletal deformities, amputations, visual impairment, chronic kidney disease, and neurological deficits. ${ }^{9}$

\section{High mortality from snakebites}

After a venomous snakebite, the management priorities include ${ }^{21}$ first aid to retard the progression of envenoming, rapid transport to a health facility, and antivenom therapy with optimal supportive care.

Deficiencies in these components, as outlined in figure 2, greatly increase vulnerability to death and adverse outcomes. $^{4}$

\section{Delayed and inappropriate treatment}

Delayed treatment can be fatal, especially beyond six hours after the bite. ${ }^{22-25}$ In many parts of South Asia, only half of patients reach a health centre within six hours of a bite, with the bite-to-treatment delay being as long as 12 to15 days in some cases. ${ }^{132627}$ As a result, $70-80 \%$ of fatalities happen before patients reach the health facility. ${ }^{1122}$ Nearly $97 \%$ of snakebite deaths in India occur in rural areas. ${ }^{11}$ Sparse distribution of health facilities in rural areas results in patients having to travel long distances for treatment. ${ }^{82829}$ Lack of affordable means of transport, particularly in remote inaccessible regions, compounds the problem. ${ }^{8}$

Communities are rarely aware of simple first aid measures. With poor access to health facilities, they often resort to traditional faith healers, who indulge in practices such as chanting, incisions,

\section{Box 1: Snakebite: the scenario in South Asia}

\section{Venomous snake species}

- Of 300 different snake species in South Asia, an estimated 70 are venomous ${ }^{13}$

- The "big four" include the common krait (Bungarus caeruleus), binocellate cobra (Naja naja), Russell's viper (Daboia russelii), and saw scaled viper (Echis carinatus). These are distributed across the subcontinent and are largely responsible for deaths and long term complications from snakebite. ${ }^{1415}$ Around $90 \%$ of snakebite deaths in India are from one of these

- Locally prevalent venomous species also contribute to the disease burden ${ }^{13-18}$

- In Bangladesh, the monocellate cobra ( $N$ kaouthia) and Wall's krait ( $B$ walli) account for a majority of cobra and krait bites respectively

- Green pit viper bites are more frequent than those by the Russell's viper in Bangladesh and Nepal. No verified reports of saw scaled vipers exist in these countries

- Hump nosed pit vipers (Hypnale sp) are the commonest cause of snakebite envenoming in Sri Lanka and are now recognised as highly venomous snakes alongside the big four

Populations affected

- With more than $70 \%$ of the largely rural South Asian population still dependent on agriculture, hunting, fishing, and forestry for its livelihood, an intersection of these snake biotopes with human dwellings and occupational activities is inevitable ${ }^{19}$

- Over half of all snakebites occur in 30-50 year old farmers and in $60-80 \%$ of cases involve ankles and feet. ${ }^{13}$ Dependence on non-mechanised, low cost farming techniques and barefoot farming practices place farmers at an increased risk of bites on the extremities. ${ }^{8}$

- Snakebites are more common among the poor. ${ }^{820}$ Poor housing conditions and inadequate lighting provide easy access to snakes into living spaces and they are not easily spotted..$^{18}$ Open houses, sleeping on the floor, and open defecation are other factors increasing the risk of snake encounters ${ }^{8}$ 


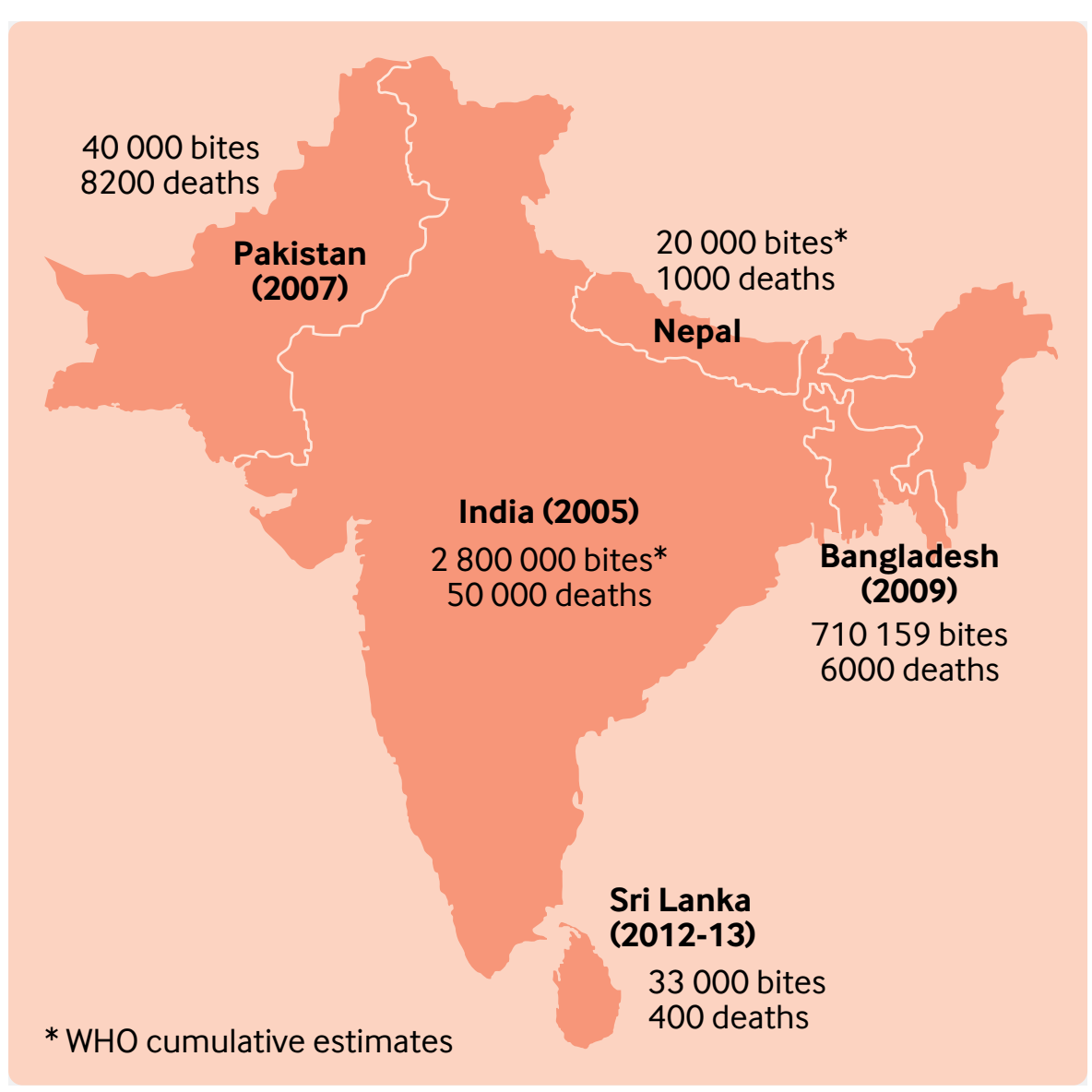

Fig 1 | Distribution of venomous snakebites and related deaths in different South Asian nations. ${ }^{10-13}$ Numbers in brackets indicate year of measurement attempts to suck venom from the bite site, tying tourniquets, or local application of herbs, cow dung, or snakestones. ${ }^{1013} 30$ These measures can delay treatment ${ }^{20} 31$ and result in increased mortality. ${ }^{1325}$

\section{Suboptimal care}

Rural health facilities in many parts of South Asia lack the infrastructure and manpower to provide timely and effective treatment. ${ }^{52932}$ Supportive care such as mechanical ventilation, dialysis, and blood transfusion is critical in the management of patients with complications such as

\section{Delayed treatment access}

- Visiting faith healers for initial treatment

- Poor rural connectivity with inadequate transport

- Shortage of doctors, antivenom, and supportive care leading to referrals

- Delayed diagnosis respiratory paralysis, acute kidney injury, and coagulopathy induced haemorrhage. Antivenom therapy alone is insufficient in their care. ${ }^{1321}$ Most rural health centres and hospitals lack critical care facilities and thereby refer patients elsewhere, resulting in treatment delays. ${ }^{33}$

Insufficient knowledge and experience among healthcare providers is also responsible for inadequate treatment. Studies among doctors in primary care and health workers in Bangladesh, India, and Pakistan show gaps in ability to recognise systemic envenoming and

\section{Suboptimal care}

- Inadequate knowledge of snakebite management

- Ineffective antivenom

- Suboptimal supportive care equipment administer antivenom. 5303435 This may be because snakebite management is not given enough focus in the medical curriculum. ${ }^{36}$ Health workers in remote settings are also reluctant to treat snakebite because of apprehension about managing antivenom associated adverse reactions. ${ }^{32}$ This apprehension is not entirely misplaced since up to $80 \%$ of those treated develop one or more antivenom associated adverse effects such as anaphylaxis, pyrogenic reactions, or serum sickness. ${ }^{13} 37$

Most South Asian countries have well formulated snakebite treatment protocols for low resource settings with a tiered referral approach. Yet these are poorly implemented with limited penetration in primary health centres. These protocols are not standardised and numerous conflicting versions exist with differing indications for antivenom administration and dosing. ${ }^{38}$

\section{Antivenom production and potency}

Underproduction and maldistribution of antivenom is a pressing challenge in the region. ${ }^{253239}$ Most South Asian countries import antivenom from Indian manufacturers-with the exception of Pakistan, which, in addition to importing Indian antivenom, also produces indigenous antivenom for domestic consumption. ${ }^{3940}$ Current production falls short of the requirements of the entire region. ${ }^{254142}$ Several manufacturers and suppliers of Indian antivenom have recently ceased operations citing reasons of price control, poor animal husbandry practices, and venom shortage. ${ }^{3943445}$ Stringent regulations on snake handling and venom procurement have hindered the establishment of new venom collection centres in India. ${ }^{43}$

Indian antivenom is produced exclusively against the big four venoms, and it is ineffective against other regionally prevalent species. ${ }^{46}$ Consequently, bites by these species are associated with poorer clinical outcomes despite the administration of large antivenom doses. ${ }^{46}$ Recent studies also reveal significant intra-species variations in the venoms of the big four based on location. ${ }^{47-51}$ Since all major Indian antivenom manufacturers source snake venom from the Irrula cooperative in south India, the available products vary in their neutralisation efficacy and clinical effectiveness against the big four venoms from other parts of South Asia. ${ }^{14434750}$ A double blind clinical trial comparing Pakistani and Indian antivenoms in 70 snakebite victims in Pakistan with deranged clotting tests and local swelling revealed quicker restoration of coagulopathy at lower doses with the Pakistani antivenom, 
suggesting greater specificity against indigenous snake species. ${ }^{52}$

Indian antivenom is manufactured in two forms-liquid and lyophilised. While lyophilised antivenoms can be stored at room temperature, liquid antivenoms should ideally be transported and stored at $2-8^{\circ} \mathrm{C}$, necessitating functional cold chain and cold storage facilities. ${ }^{534}$ The lack of an effective cold chain and unreliable refrigeration facilities in rural areas render it ineffective. ${ }^{355}$ Non-standard manufacturing practices also result in variable antivenom effectiveness. ${ }^{556}$ Stringent measures to contain or withdraw substandard batches are lacking. The government run Central Drugs Laboratory in India screens antivenoms for potency. ${ }^{57}$ These tests cover limited brands, however, and currently batches from only four of the six main antivenom manufacturers are screened. ${ }^{58}$

\section{Why do these problems persist?}

Over the years, snakebite mitigation has not had enough attention in the public health agenda of the region. Lack of good quality epidemiological data on snakebites and their impact and affliction of mainly poor and vulnerable populations have contributed to this. Figure 3 summarises these challenges.

\section{Lack of research and innovation}

With the exception of Sri Lanka, South Asia has a severe dearth of quality data on snakebite epidemiology, largely because of the skewed reliance by national agencies on hospital based studies. ${ }^{13}$ In a region where a considerable proportion of patients may die before reaching a hospital or preferentially

\section{Barriers to improvement}

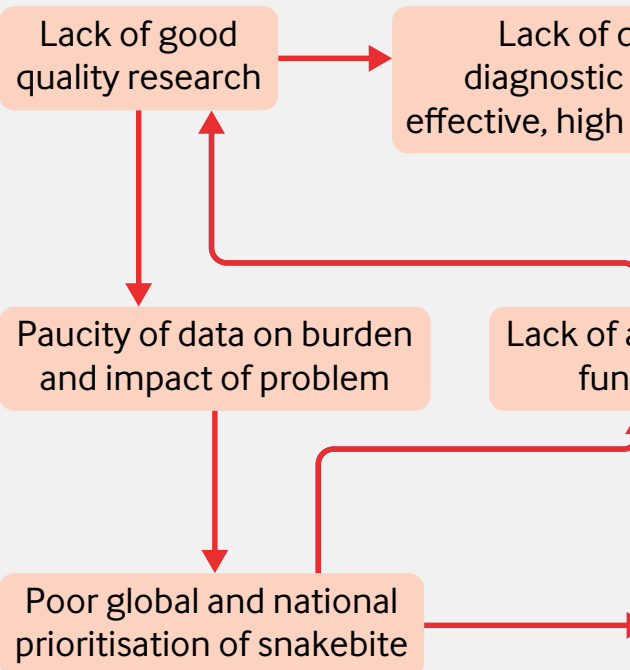

attend traditional healers, snakebites simply pass unreported and hospital based studies tend to underestimate the problem. ${ }^{59}$ There are few studies on chronic disability burden and socioeconomic impact of snakebites. ${ }^{60}$

There is limited evidence to guide treatment protocols. Most studies on snake distribution, ecology, envenoming profiles, and intra-species venom variation do not encompass all medically important species and are limited in geographical extent. ${ }^{10111222}$ Studies on preclinical efficacy, pharmacokinetics, clinical effectiveness, and safety of current antivenoms are lacking. ${ }^{37395661}$ The optimal dose of antivenom is still debated and regional clinical trials offer conflicting evidence. A systematic review of 10 open label randomised controlled trials in the Indian subcontinent on optimal antivenom dose concluded that there is very low quality evidence to guide practice and further research is needed. ${ }^{62}$

\section{Political and financial barriers}

Because of the paucity of data on snakebite epidemiology, socioeconomic impact, and disability burden, most South Asian governments have failed to prioritise snakebite as a matter of national importance needing concerted action and allocation of health resources. Snakebite mitigation strategies are practically non-existent in South Asia and national prevention awareness programmes are largely overlooked. ${ }^{13}$

Snakebite envenoming is also not recognised as a public health problem at the level of the South Asian Association for Regional Co-operation (SAARC). It does not feature in the organisation's list of priority diseases-which includes leprosy and rabies among others-which benefit from numerous initiatives aimed at setting up integrated networks and nodal centres for regional training, research, disease eradication, and information dissemination. ${ }^{63}$ This lack of national and regional prioritisation has resulted in the matter being overlooked in the global health agenda, until its recognition as a neglected tropical disease by WHO in 2017.

\section{The way forward}

A substantive global target for neglected tropical diseases exists in the form of the Sustainable Development Goal 3.3 to "end the epidemics" of these diseases by 2030 . $^{4}$ The recent inclusion of snakebite as a neglected tropical disease should mean greater funding for research and mitigation strategies. We present below key priorities for South Asian countries. Establishing national snake envenoming mitigation programmes in each country can help in effective and centralised execution of these efforts.

\section{Strengthen regional cooperation}

A regional collaborative centre for snakebite research and advocacy and nodal training centres for envenoming management must be established along the lines of the SAARC tuberculosis and HIV/AIDS centre. ${ }^{64}$ This would serve as a platform to bring together research and policy experts working on snakebite mitigation from across disciplines. The centre would help collate and monitor data on snakebite incidence in the region; facilitate collaborative research and technology transfers between nations;

\section{Poor outcome determinants}

Deficiencies in healthcare and transport infrastructure
Lack of legislative support on national

level treatment guidelines, healthcare worker training and community awareness programmes, and quality control
Death or disability

antivenom

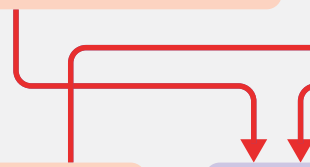

Delayed diagnosis and poor treatment quality Delay in access to healthcare
Improper first aid

Fig 3 | The intricate web of poor outcome determinants interacting with barriers to improvement 
and support national snakebite mitigation efforts through policy guidance and technical support.

\section{Improve reporting}

Setting up sentinel reporting systems in different parts of each country can help improve the availability of epidemiological information on snakebites. The Big 4 Mapping Project (http://snakebiteinitiative.in/ snake) under the Global Snakebite Initiative provides an interesting approach to understanding the distribution of snake species across India, with volunteers providing real time information on snake sightings. ${ }^{65}$ Designating snakebite as a notifiable disease would further improve reporting from health facilities. To achieve standardisation, health workers should be encouraged to use the specific international classification of diseases code T63.0 (toxic effect of contact with snake venom) in certification of death in snakebite victims. ${ }^{21}$ In unclear cases of snakebite death, immunological assays can be used to establish the cause. ${ }^{66}$

\section{Increase awareness of preventive measures}

The distinctive epidemiology combined with knowledge of snake habitats and periods of activity is important in planning preventive measures. Sleeping under a mosquito net and on a bed above ground level have been protective against krait and cobra bites, in both anecdotal reports and community based observational studies in India, Nepal, and Sri Lanka. ${ }^{676869}$ Protective footwear was distributed among paddy farmers in Myanmar 20 years ago, but its impact in reducing snakebite is unclear. ${ }^{70}$

Lack of awareness and high illiteracy among communities are linked to poor implementation of preventive measures such as keeping domestic areas free of rubbish, rubble, and firewood; controlling rodent populations; constructing snake proof houses; and using protective footwear. ${ }^{132671}$ Snakebite prevention and first aid training programmes targeted towards at-risk populations are essential to reduce snakebites and improve initial response.

Dissuading those bitten by snakes from visiting faith healers can be a challenge since the latter are an integral part of the fabric of many South Asian societies. A non-governmental organisation in eastern India has been trying to engage with faith healers through workshops to promptly refer snakebite victims to health centres. ${ }^{32}$

\section{Strengthen rural health services}

Ensuring efficient ambulance transport and facilities for dialysis, mechanical ventila- tion, blood transfusion, and intensive care in rural areas will be vital to prevent deaths from snakebites. A few regional initiatives have attempted to tackle these matters. In Nepal, a network of motorcycle volunteers was organised to transport snakebite victims promptly, on otherwise unpassable trails, to health centres. This simple intervention, along with community education, considerably reduced incidence and fatality from snakebites. ${ }^{72}$ In India, free ambulance services initiated as public-private partnerships have sought to provide rapid access to care. ${ }^{73}$ The full impact of this initiative is hindered, however, by a shortage of services in rural areas, suboptimal response times or non-attendance of calls, inadequately trained paramedics, and the absence of in-transit antidote therapy and standardised resuscitation protocols. ${ }^{7374}$

Healthcare providers, particularly those practising in high burden rural areas, must be trained in using standard treatment guidelines for snakebite management. Hands-on training in airway management and treatment of anaphylaxis must also be included. Nationwide training of health workers and paramedics has been initiated in Nepal, but the impact of this programme is yet to be assessed. Integrating snakebite management in the medical curriculum and organising workshops using locally adaptable training modules based on WHO guidelines will help. Compliance with guidelines must be ensured and an audit of deaths and adverse events must be regularly conducted at the district level.

\section{Enhance production, potency, and safety of} antivenom

Measures to revive antivenom manufacturing units that have ceased production, increase snake venom availability, and improve animal husbandry practices will be critical to step up production in the region. Legislative amendments to ease restrictive Indian laws on snake capture and venom extraction need to be considered. Subsidised antivenom should be made available in sufficient quantities in both government and private health facilities and monitored for storage under appropriate conditions. Venom collection must be expanded to multination regional venom cooperatives. Establishing serpentariums for captive husbandry and adherence to WHO recommended standards during venom collection and antivenom manufacture would improve the quality and safety of antivenom. Regulatory bodies for quality control of Indian antivenoms should screen batches from all manufacturers and formulate basic minimum standards for potency and quality based on WHO guidelines. ${ }^{75}$

There is a need to support development of newer antivenoms against locally prevalent snake species. A collaborative initiative between Costa Rica, Sri Lanka, and the US to develop newer antivenoms specific to Sri Lanka's major snake species is an example in this direction. ${ }^{7677} \mathrm{~A}$ project initiated in 2018 in Bangladesh aims to establish a geographically representative snake venom production, research, and preclinical testing facility in Chittagong.

\section{Box 2: Recommendations for future research}

- Large, representative, community based epidemiological studies to estimate the true burden of snakebite morbidity and mortality, and socioeconomic impact

- Large, well designed clinical trials to establish safety, efficacy, and optimal dose of antivenoms

- Developing and testing preclinical efficacy of new antivenoms involving all medically important snake species across South Asia. These could include different regional antivenoms with specificity against local snake species in addition to the big four, or consist of two separate expanded polyspecific antivenoms against major South Asian viperid and elapid species, respectively

- Studies on envenoming syndromes to establish species-syndrome correlation and aid early identification of snake species. This could help clinicians anticipate complications and initiate appropriate treatment7879

- Diagnostic tools to identify snake species that screen for species specific venom proteins or amplify and sequence bite site snake DNA. Technical support from countries like Australia, where commercial point-of-care venom detection kits are marketed for indigenous species, could be sought to develop improved kits for South Asian snake species. ${ }^{79}$ DNA aptamers have recently been used in venom based identification of South East Asian krait species ${ }^{80}$

- Clinical evaluation of pharmacological interventions to retard venom transit from bite site to circulation by slowing lymphatic flow and thereby preventing systemic toxicity in animals. These could be a promising adjunct for snakebite first aid measures ${ }^{81}$ 


\section{Research and innovation}

The global focus on snakebite provides an opportunity to boost research in this neglected area. Box 2 lists areas for further research. This would help generate critical evidence to inform policy making and more effective, economical, and feasible preventive and treatment measures.

We thank Malik Fernando, secretary, Sri Lanka Medical Association (SLMA) Snakebite Committee, and Anand Zachariah, professor of medicine, Christian Medical College, Vellore, for their instructive comments on this manuscript.

Contributors and sources: This article is based on a PubMed search for articles and studies published between 1980 and 2018 using the MeSH terms: "(epidemiology, diagnosis and treatment guidelines) and (snake, snakebite, envenoming, venom, venomics and antivenomics)." Additional articles were obtained by citation tracking of review and original articles. We also drew on conference proceedings and original research conducted by the authors. RR formulated and wrote the initial draft. All authors searched literature, framed manuscript content, contributed to critical revisions, and approved the final version. RR is the guarantor.

Competing interests: We have read and understood BMJ policy on declaration of interests and have no interests to declare.

Provenance and peer review: Commissioned; externally peer reviewed.

This article is one of a series commissioned by The BMJ in collaboration with the Drugs for Neglected Diseases initiative (DNDi). The BMJ retained full editorial control over external peer review, editing, and publication. Open access fees are funded by the DNDi, Geneva.

Ravikar Ralph, associate professor ${ }^{1}$

Sanjib Kumar Sharma, professor and head ${ }^{2}$ Mohammad Abul Faiz, professor of medicine (retired) ${ }^{3}$

Isabela Ribeiro, scientific lead ${ }^{4}$

Suman Rijal, director ${ }^{5}$

François Chappuis, professor ${ }^{6}$

Ulrich Kuch, head ${ }^{7}$

${ }^{1}$ Department of Internal Medicine, Christian Medical College, Vellore, India

${ }^{2}$ Department of Internal Medicine, BP Koirala Institute of Health Sciences, Dharan, Kathmandu, Nepal ${ }^{3}$ Dev Care Foundation, Dhaka, Bangladesh ${ }^{4}$ Dynamic Portfolio, Drugs for Neglected Diseases initiative (DNDi), Geneva, Switzerland

\section{${ }^{5}$ DNDi, New Delhi, India}

${ }^{6}$ Division of Tropical and Humanitarian Medicine, Geneva University Hospitals, Geneva, Switzerland ${ }^{7}$ Department of Tropical Medicine and Public Health, Institute of Occupational Medicine, Social Medicine and Environmental Medicine, Goethe University Frankfurt, Germany

Correspondence to: Ravikar Ralph

ravikar_ralph@yahoo.com

\section{(c) (1) \& OPEN ACCESS}

This is an Open Access article distributed in accordance with the Creative Commons Attribution Non Commercial (CC BY-NC 4.0) license, which permits others to distribute, remix, adapt, build upon this work non-commercially, and license their derivative works on different terms, provided the original work is properly cited and the use is non-commercial. See: http://creativecommons.org/ licenses/by-nc/4.0/.

\section{A) Check for updates}

1 Prevalence of snakebite envenoming. World Health Organization. www.who.int/snakebites/ epidemiology/en

2 Kasturiratne A, Wickremasinghe AR, de Silva N, et al. The global burden of snakebite: a literature analysis and modelling based on regional estimates of envenoming and deaths. PLoS Med 2008;5:e218. doi:10.1371/journal.pmed.0050218

3 Simpson ID, Norris RL. The global snakebite crisis--a public health issue misunderstood, not neglected. Wilderness Environ Med 2009;20:43-56. doi:10.1580/08-WEME-CON-263.1

4 Longbottom J, Shearer FM, Devine M, et al. Vulnerability to snakebite envenoming: a global mapping of hotspots. Lancet 2018;392:673-84 doi:10.1016/S0140-6736(18)31224-8

5 Sachan D. The snake in the room: snakebite's huge death toll demands a global response. $B M$ J 2018;361:k2449. doi:10.1136/bmi.k2449

6 World Health Organization. Addressing the burden of snakebite envenoming. 25 January 2018. http:// apps.who.int/gb/ebwha/pdf_files/EB142/B142_R4en.pdf?ua $=1$

7 Gutiérrez IM, Warrell DA, Williams DJ, et al, Global Snakebite Initiative. The need for full integration of snakebite envenoming within a global strategy to combat the neglected tropical diseases: the way forward. PLoS Negl Trop Dis 2013;7:e2162. doi:10.1371/journal.pntd.0002162

8 Harrison RA, Hargreaves A, Wagstaff SC, Faragher B, Lalloo DG. Snake envenoming: a disease of poverty. PLoS Negl Trop Dis 2009;3:e569. doi:10.1371/ journal.pntd.0000569

9 Jayawardana S, Arambepola C, Chang T, Gnanathasan A. Long-term health complications following snake envenoming. J Multidiscip Health 2018;11:279-85. doi:10.2147/JMDH.S126648

10 Rahman R, Faiz MA, Selim S, et al. Annual incidence of snake bite in rural bangladesh. PLoS Negl Trop Dis 2010;4:e860. doi:10.1371/journal.pntd.0000860

11 Mohapatra B, Warrell DA, Suraweera W, et al, Million Death Study Collaborators. Snakebite mortality in India: a nationally representative mortality survey. PLoS Negl Trop Dis 2011;5:e1018. doi:10.1371/ journal.pntd.0001018

12 Ediriweera DS, Kasturiratne A, Pathmeswaran A, et al. Mapping the risk of snakebite in Sri Lanka: a national survey with geospatial analysis. PLoS Negl Trop Dis 2016;10:e0004813. doi:10.1371/journal. pntd.0004813

13 Alirol E, Sharma SK, Bawaskar HS, Kuch U, Chappuis F. Snake bite in South Asia: a review. PLoS Negl Trop Dis 2010;4:e603. doi:10.1371/journal.pntd.0000603

14 Warrell DA, Gutiérrez JM, Calvete JJ, Williams D. New approaches \& technologies of venomics to meet the challenge of human envenoming by snakebites in India. Indian I Med Res 2013;138:38-59.

15 Sri Lanka Medical Association. Epidemiology of snakebite in Sri Lanka. http://slma.lk/wp-content/ uploads/2017/11/2.Epidemiology-of-snakebite.pdf.

16 Sharma SK, Pandey DP, Shah KB, et al. Venomous snakes of Nepal: a photographic guide. February 2013. www.bik-f.de/files/publications/kuch venomous_snakes_of_nepal_-_english_edition.pdf.

17 Shivanthan MC, Yudhishdran J, Navinan R, Rajapakse S. Hump-nosed viper bite: an important but under-recognized cause of systemic envenoming. I Venom Anim Toxins Incl Trop Dis 2014;20:24 doi:10.1186/1678-9199-20-24

18 Maduwage K, Isbister GK, Silva A, Bowatta S, Mendis S, Gawarammana I. Epidemiology and clinical effects of hump-nosed pit viper (Genus: Hypnale) envenoming in Sri Lanka. Toxicon 2013;61:11-5. doi:10.1016/j.toxicon.2012.10.013
19 Food and Agriculture Organization of the United Nations. FAO in India: India at a glance. www.fao.org/ india/fao-in-india/india-at-a-glance/en.

20 Rao CP, Shivappa P, Mothi VR. Fatal snake bites - sociodemography, latency pattern of injuries. Occup Med Toxicol 2013;8:7. doi:10.1186/17456673-8-7

21 Warrell DA. Snake bite. Lancet 2010;375:77-88. doi:10.1016/S0140-6736(09)61754-2

22 Sharma SK, Koirala S, Dahal G, Sah C. Clinicoepidemiological features of snakebite: a study from Eastern Nepal. Trop Doct 2004;34:20-2. doi:10.1177/004947550403400108

23 Suchithra N, Pappachan JM, Sujathan P. Snakebite envenoming in Kerala, South India: clinical profile and factors involved in adverse outcomes. Emerg Med J 2008;25:200-4. doi:10.1136/ emj.2007.051136

24 Narvencar K. Correlation between timing of ASV administration and complications in snake bites. J Assoc Physicians India 2006;54:717-9.

25 Longkumer T, Armstrong LJ, Finny P. Outcome determinants of snakebites in North Bihar, India: a prospective hospital based study. I Venom Res 2017;8:14-8.

26 Bhelkar SM, Chilkar SD, Morey SM. Study of snake bite cases admitted in tertiary care hospital in Nagpur. Int J Community Med Public Health 2017:4:1597-602 doi:10.18203/2394-6040. ijcmph20171770.

27 Chauhan S, Faruqi S, Bhalla A, Sharma N, Varma S, Bali J. Pre-hospital treatment of snake envenomation in patients presented at a tertiary care hospital in Northwestern India. I Venom Anim Toxins Trop Dis 2005; 11:275-82

28 Singh S, Badaya S. Health care in rural India: A lack between need and feed. South Asian J Cancer 2014;3:143-4. doi:10.4103/2278-330X.130483

29 Bajpai V. The challenges confronting public hospitals in India, their origins, and possible solutions. Advances in Public Health 2014. www.hindawi.com/ journals/aph/2014/898502.

30 Chauhan S, Faruqi S, Bhalla A, Sharma N, Varma S, Bali J. Pre-hospital treatment of snake envenomation in patients presented at a tertiary care hospital in Northwestern India. J Venom Anim Toxins Trop Dis 2005; 11:275-82.

31 Majumder D, Sinha A, Bhattacharya SK, Ram R, Dasgupta U, Ram A. Epidemiological profile of snake bite in south 24 Parganas district of West Bengal with focus on underreporting of snake bite deaths. Indian J Public Health 2014;58:17-21. doi:10.4103/0019557X.128158

32 Bhaumik S. Snakebite: a forgotten problem. BMJ 2013;346:f628. doi:10.1136/bmj.f628

33 Kalantri S, Singh A, Joshi R, et al. Clinical predictors of in-hospital mortality in patients with snake bite: a retrospective study from a rural hospital in central India. Trop Med Int Health 2006;11:22-30. doi:10.1111/j.1365-3156.2005.01535.x

34 Simpson ID. A study of the current knowledge base in treating snake bite amongst doctors in the high-risk countries of India and Pakistan: does snake bite treatment training reflect local requirements? Trans $R$ Soc Trop Med Hyg 2008;102:1108-14. doi:10.1016/j. trstmh.2008.04.013

35 Ahsan H, Rahman M, Amin R, Chowdhury E. Status of snake bite at a rural community of Bangladesh: a survey. J Curr Adv Med Res. 2018;4:17-22 doi:10.3329/jcamr.v4i1.36170.

36 Subedi N, Paudel IS, Khadka A, Shrestha U, Mallik VB, Ankur KC. Knowledge of first aid methods and attitude about snake bite among medical students: a cross sectional observational study. J Occup Med Toxicol 2018;13:26. doi:10.1186/s12995-018-0210-0

37 de Silva HA, Ryan NM, de Silva HJ. Adverse reactions to snake antivenom, and their prevention and treatment. BrJ Clin Pharmacol 2016;81:446-52. doi:10.1111/bcp.12739 
38 Bhaumik S. Problems with treating snake bite in India. BMJ 2016;352:i103. doi:10.1136/bmj.i103

39 Williams DJ, Gutiérrez J-M, Calvete JJ, et al. Ending the drought: new strategies for improving the flow of affordable, effective antivenoms in Asia and Africa. J Proteomics 2011;74:1735-67. doi:10.1016/j. jprot.2011.05.027

40 National Institute of Health Islamabad. SERA processing lab. www.nih.org.pk/1255-2.

41 Gautram M. The perennial cry for antivenom. Kathmandu Post. http://kathmandupost.ekantipur. com/printedition/news/2013-08-19/the-perennialcry-for-antivenom.html.

42 Shrestha BR, Pandey DP, Acharya KP, Thapa-Magar C, Mohamed F, Isbister GK. Effective, polyvalent, affordable antivenom needed to treat snakebite in Nepal. Bull World Health Organ 2017:95:718-9. doi:10.2471/BLT.17.195453

43 Whitaker R, Whitaker S. Venom, antivenom production and the medically important snakes of India. Curr Sci 2012;103:9.

44 Sharma A. Venom shortage forces CRI to scale down anti-sera output. Tribune. 1 May 2015. www. tribuneindia.com/news/himachal/community/ venom-shortage-forces-cri-to-scale-down-anti-seraoutput/74433.html.

45 Hemalatha K. Shortage and decreasing efficacy of ASVs: India faces a snakebite treatment double whammy. Mongabay. 27 February 2018. https:// india.mongabay.com/2018/02/27/shortage-anddecreasing-efficacy-of-asvs-india-faces-a-snakebitetreatment-double-whammy.

46 Ariaratnam CA, Thuraisingam V, Kularatne SA, et al. Frequent and potentially fatal envenoming by humpnosed pit vipers (Hypnale hypnale and $H$. nepa) in Sri Lanka: lack of effective antivenom. Trans $R$ Soc Trop Med Hyg 2008;102:1120-6. doi:10.1016/j. trstmh.2008.03.023

47 Kalita B, Mackessy SP, Mukherjee AK. Proteomic analysis reveals geographic variation in venom composition of Russell's Viper in the Indian subcontinent: implications for clinical manifestations post-envenomation and antivenom treatment. Expert Rev Proteomics 2018;15:837-49. doi:10.1080/147 89450.2018.1528150

48 Dissanayake DSB, Thewarage LD, Waduge RN, Ranasinghe JGS. The venom of spectacled cobra (Elapidae: naja naja): in vitro study from distinct geographical origins in Sri Lanka. J Toxicol 2018. www.hindawi.com/journals/jt/2018/7358472.

49 Shashidharamurthy R, Jagadeesha DK, Girish KS, Kemparaju K. Variations in biochemical and pharmacological properties of Indian cobra (Naja naja naja) venom due to geographical distribution. Mol Cell Biochem 2002;229:93-101. doi:10.1023/A:1017972511272

50 Sintiprungrat K, Watcharatanyatip K, Senevirathne WDST, et al. A comparative study of venomics of Naja naja from India and Sri Lanka, clinical manifestations and antivenomics of an Indian polyspecific antivenom. J Proteomics 2016;132:131-43. doi:10.1016/j.jprot.2015.10.007

51 Sharma M, Gogoi N, Dhananjaya BL, Menon JC, Doley R. Geographical variation of Indian Russell's viper venom and neutralization of its coagulopathy by polyvalent antivenom. Toxin Rev 2014:33:7-15 doi:1 0.3109/15569543.2013.855789.

52 Qureshi H, Alam SE, Mustufa MA, Nomani NK, Asnani L, Sharif M. Comparative cost and efficacy trial of Pakistani versus Indian anti snake venom. J Pak Med Assoc 2013;63:1129-32.

53 VINS BioProducts Limited. Snake venom antiserum. http://vinsbio.in/antisnake.

54 Bharat Serums and Vaccines Limited. www. bharatserums.com/emergency.html.

55 Pandey K. Half the global snake bite deaths happen in India. Why are we not prepared? 11 September 2017. www.downtoearth.org.in/news/serpentineproblem-58396.

56 Maduwage K, Silva A, O'Leary MA, Hodgson WC Isbister GK. Efficacy of Indian polyvalent snake antivenoms against Sri Lankan snake venoms: lethality studies or clinically focussed in vitro studies. Sci Rep 2016;6:26778. doi:10.1038/ srep26778

57 Central Drugs Laboratory. Antisera/antitoxin unit https://cdlkasauli.gov.in/CDL_KASAULI/antisera_ vacc.

58 Central Drugs Laboratory. List of manufacturers with product: antisera unit. https://cdlkasauli.gov.in/ CDL_KASAULI/antisera_vacc_manf

59 Fox S, Rathuwithana AC, Kasturiratne A, Lalloo DG, de Silva HJ. Underestimation of snakebite mortality by hospital statistics in the Monaragala District of Sri Lanka. Trans R Soc Trop Med Hyg 2006;100:693-5. doi:10.1016/j.trstmh.2005.09.003

60 Kasturiratne A, Pathmeswaran A, Wickremasinghe $A R$, et al. The socio-economic burden of snakebite in Sri Lanka. PLoS Negl Trop Dis 2017;11:e0005647. doi:10.1371/journal.pntd.0005647

61 Alirol E, Sharma SK, Ghimire A, et al. Dose of antivenom for the treatment of snakebite with neurotoxic envenoming: Evidence from a randomised controlled trial in Nepal. PLoS Negl Trop Dis 2017;11:e0005612. doi:10.1371/journal.pntd.0005612

62 Das RR, Sankar J, Dev N. High-dose versus low-dose antivenom in the treatment of poisonous snake bites: A systematic review. Indian J Crit Care Med 2015;19:340-9. doi:10.4103/0972-5229.158275

63 South Asian Association for Regional Cooperation. http://training.itcilo.it/actrav_cdrom1/english/ global/blokit/saarc.htm

64 South Asian Association for Regional Cooperation TB and HIV/AIDS Centre. www.saarctb.org/new/saarctb-and-hivaids-centre.

65 Big four mapping project. http://snakebiteinitiative. in/snake

66 Brunda G, Sashidhar RB. Epidemiological profile of snake-bite cases from Andhra Pradesh using immunoanalytical approach. Indian J Med Res 2007;125:661-8

67 Mallik S, Singh SR, Sahoo J, Mohanty MK. mosquito net: an underrecognized protection measure against snakebites. Int J Prev Med 2017;8:1. doi:10.4103/2008-7802.197686

68 Chappuis F, Sharma SK, Jha N, Loutan L, Bovier PA. Protection against snake bites by sleeping under a bed net in southeastern Nepal. Am / Trop Med Hyg 2007;77:197-9. doi:10.4269/ ajtmh.2007.77.197
69 Rodrigo C, Kirushanthan S, Gnanathasan A. Prevention of krait bites by sleeping above ground preliminary results from an observational pilot study. J Occup Med Toxicol 2017;12:10.doi:10.1186/ s12995-017-0156-7

70 Pe T, Myint AA, Kyu KA, Toe MM. Acceptability study of protective boots among farmers of Taungdwingyi Township. Myanmar Health Sci Res / 1998;10: 57-60.

71 Kularatne SA. Common krait (Bungarus caeruleus) bite in Anuradhapura, Sri Lanka: a prospective clinical study, 1996-98. Postgrad Med J 2002;78:276-80. doi:10.1136/pmj.78.919.276

72 Sharma SK, Bovier P, Jha N, Alirol E, Loutan L, Chappuis F. Effectiveness of rapid transport of victims and community health education on snake bite fatalities in rural Nepal. Am / Trop Med Hyg 2013;89:145-50. doi:10.4269/ajtmh.12-0750

73 Rajasulochana SR, Maurya AD. 108 in crisis: complacency and compromise undermine emergency services' potential. 28 June 2018. Economic and Political Weekly. www.epw.in/ engage/article/108-services-are-plaguedcomplacency-and.

74 Singh J. Ambulance emergency. 7 June 2015. www.downtoearth.org.in/coverage/ambulanceemergency-40605.

75 World Health Organization. WHO guidelines for the production, control and regulation of snake antivenom immunoglobulins. www.who.int/bloodproducts/ snake antivenoms/snakeantivenomguide/en.

76 Keyler DE, Gawarammana I, Gutiérrez JM, Sellahewa $\mathrm{KH}$, McWhorter K, Malleappah R. Antivenom for snakebite envenoming in Sri Lanka: the need for geographically specific antivenom and improved efficacy. Toxicon 2013;69:90-7. doi:10.1016/j. toxicon.2013.01.022

77 Villalta M, Sánchez A, Herrera M, et al. Development of a new polyspecific antivenom for snakebite envenoming in Sri Lanka: Analysis of its preclinical efficacy as compared to a currently available antivenom. Toxicon 2016;122:152-9. doi:10.1016/ toxicon.2016.10.007

78 Bhadrapura Lakkappa D, Menon J, Joseph J, Kumar D, Oommen O. Snake Venom Detection Kit (SVDK): update on current aspects and challenges. In: Toxinology: Clinical toxinology in Asia Pacific and Africa. Springer, 2015 379-400.

79 Sharma SK, Kuch U, Höde P, et al. Use of molecular diagnostic tools for the identification of species responsible for snakebite in Nepal: a pilot study. PLoS Negl Trop Dis 2016;10:e0004620. doi:10.1371/journal.pntd.0004620

80 Ye F, Zheng Y, Wang X, et al. Recognition of Bungarus multicinctus venom by a DNA aptamer against $\beta$-bungarotoxin. PLoS One 2014;9:e105404. doi:10.1371/journal.pone.0105404

81 van Helden DF, Thomas PA, Dosen PJ, Imtiaz MS, Laver DR, Isbister GK. Pharmacological approaches that slow lymphatic flow as a snakebite first aid. PLOS Negl Trop Dis 2014;8:e2722. doi:10.1371/journal. pntd.0002722

Cite this as: $B M J$ 2019;364:k5317

http://dx.doi.org/10.1136/bmj.k5317 